\title{
Novas características para diferenciação de cultivares de soja pela análise discriminante
}

\author{
New traits for differentiation of soybeans using discriminant analysis
}

\author{
Ana Paula Oliveira Nogueira ${ }^{{ }^{*}}$ Tuneo Sediyama ${ }^{\mathrm{II}}$ Cosme Damião Cruz ${ }^{\mathrm{III}}$ Múcio Silva Reis ${ }^{\mathrm{II}}$ \\ Derval Gomes Pereira ${ }^{I V}$ Marcelo Jangarelli ${ }^{\mathrm{I}}$
}

\section{RESUMO}

A diferenciação de cultivares é realizada por margem mínima de descritores específicos de cada espécie. Atualmente, são usados cerca de 38 descritores entre os obrigatórios e os adicionais para diferenciar cultivares de soja. Entretanto, estes ainda são insuficientes, o que torna evidente a necessidade de ampliar a lista de descritores utilizados, os quais devem ser previamente identificados e avaliados. $O$ presente trabalho teve como objetivos identificar e avaliar novas características para fins de diferenciação de cultivares de soja. A pesquisa foi realizada em casa de vegetação do Departamento de Fitotecnia (DFT), da Universidade Federal de Viçosa (UFV), e foram realizados quatro experimentos em quatro épocas diferentes (dois no verão e dois no inverno). Os tratamentos foram constituídos de 11 cultivares de soja. O delineamento experimental foi inteiramente aleatorizado com cinco repetições, em que cada unidade experimental foi constituída por um vaso com duas plantas. Foram avaliadas as características comprimento do hipocótilo $(\mathrm{CH})$, comprimento do epicótilo (CE), comprimento do pecíolo da folha unifoliolada (CPFU), coeficiente da forma da base da folha unifoliolada (CFB), coeficiente da largura da base da folha unifoliolada (CLB), comprimento do pecíolo da primeira folha trifoliolada (CPFT) e comprimento da raque do folíolo terminal da primeira folha trifoliolada (CRFT). Para o estudo, foi realizada a análise discriminante de ANDERSON (1958) e as análises estatísticas foram realizadas utilizando o aplicativo computacional em Genética e Estatística, denominado Programa Genes. Para todas as características analisadas, foram observadas diferenças significativas nas quatro épocas de semeaduras. Pela análise discriminante, foi possível distinguir cultivares de soja. Conclui-se que as características são úteis como descritoras adicionais de cultivares de soja.

Palavras-chave: Glycine max, descritores, melhoramento.

\begin{abstract}
Cultivar differentiation is carried out by the least margin of specific descriptors in each species. Nowadays, approximately 38 descriptors, including the obligatory and additional ones, are used to differentiate soybean cultivars. Since these descriptors are still not enough, it is necessary to increase the number of descriptors used, which should be previously identified and evaluated. The objectives of this study were to identify and evaluate new traits for the differentiation of soybean cultivars. The experiments were conducted in a greenhouse at the Plant Science Department of the Federal University of Viçosa at four different times (two during summer and two during winter). The treatments consisted of 11 soybean cultivars arranged in a complete randomized design with five replicates. Each experimental unit consisted of one pot with two plants. The following characteristics were evaluated: hypocotyl length (CH), epicotyl length (CE), petiole length of the unifoliate leaf (CPFU), base shape coefficient of the unifoliate leaf (CFB), base width coefficient of the unifoliate leaf (CLB), petiole length of the first trifoliate leaf (CPFT) and rachis length of terminal leaflet in the first trifoliate leaf (CRFT). Anderson's discriminant analysis was performed, and statistical analyses were carried out using the Genetics and Statistics software 'Programa Genes'. Significant differences were found for all characteristics in the four sowing times. Discriminant analysis allowed the differentiation of the soybean cultivars. It was concluded that the characteristics are useful as additional descriptors of soybean cultivars.
\end{abstract}

Key words: Glycine max, descriptors, improvement.

\footnotetext{
'Programa de Pós-graduação em Genética e Melhoramento, Universidade Federal de Viçosa (UFV), 36570-000, Viçosa, MG, Brasil. E-mail: anap812004@yahoo.com.br. *Autor para correspondência.

"Departamento de Fitotecnia (DFT), UFV, Viçosa, MG, Brasil.

IIIDepartamento de Biologia Geral (DBG), UFV, Viçosa, MG, Brasil.

${ }^{\text {IV }}$ Departamento de Química e Exatas, Universidade Estadual do Sudoeste da Bahia (UESB), Jequié, BA, Brasil.
} 


\section{INTRODUÇÃO}

A soja é uma das culturas que apresenta maior crescimento em área plantada no segmento agroindustrial brasileiro. Sua expansão e o estabelecimento de fronteiras agrícolas somente foi possível devido ao desenvolvimento de cultivares com alta produtividade, ampla adaptação às diferentes condições edafoclimáticas e resistentes a pragas e doenças (EMBRAPA, 2006).

No Brasil, o melhoramento genético teve incentivo de grande impacto a partir de 1997, quando foi sancionada a Lei ${ }^{\circ}$. 9456, que trata da proteção de cultivares. A proteção dos direitos intelectuais sobre a cultivar se efetua mediante a obtenção de um certificado de proteção concedido pelo Serviço Nacional de Proteção de Cultivares (SNPC) (NETO et al., 2005). Para que uma cultivar seja protegida, é necessário comprovar que ela é distinta, homogênea e estável. A distinguibilidade de uma cultivar refere-se à diferença clara de qualquer outra cultivar cuja existência na data do período de proteção seja reconhecida (GRILLI, 2005).

A diferenciação de cultivares é realizada por margem mínima de descritores específicos de cada espécie (NETO et al., 2005). Atualmente, são usados cerca de 38 descritores entre os obrigatórios e os adicionais para diferenciar cultivares de soja, entretanto, estes ainda são insuficientes para distinguir as cultivares, o que torna evidente a necessidade de ampliar a lista de descritores utilizados. Desse modo, estes devem ser previamente identificados e avaliados.

Há relatos de efeitos relacionados a diferenças genéticas para o comprimento do hipocótilo (KNITTLE \& BURRIS, 1979; NÓBREGA \& VIEIRA, 1995). A variação no comprimento do hipocótilo tem sido atribuída às diferenças entre cultivares (COSTA et al., 1999). Alguns autores concordam que sementes de maior tamanho originam plântulas com hipocótilo mais curto que sementes de tamanho menor (COSTA et al., 1999), no entanto, existem cultivares em que o comprimento do hipocótilo independe do tamanho da semente (KNITTLE \& BURRIS, 1979).

Em um estudo de caracterização de cultivares no Sul do Brasil, Rossini et al. (1995) avaliaram o comprimento do hipocótilo em condições de laboratório e observaram que uma mesma cultivar, proveniente de diferentes locais de produção, apresentou hipocótilos curtos, médios e longos, quando comparada às testemunhas. Porém, seis cultivares das 26 avaliadas tiveram consistentemente hipocótilo curto independentemente do local de produção.

As plantas de soja, ao longo do seu desenvolvimento, possuem quatro tipos distintos de folhas: as cotiledonares, as unifolioladas, as trifolioladas, que possuem tamanhos, formatos e posicionamentos diferentes, e os prófilos, pequenos e pouco diferenciados (MÜLLER, 1981).

Com intuito de separar sementes que possuem os mesmos caracteres, DORCHESTER (1945) utilizou como características auxiliares a forma da base da folha unifoliolada (acunheada, troncada e auriculada), bem como a razão da maior largura da folha pelo comprimento, concluindo que a forma da folha apresenta características bem definidas, embora haja variação dentro de uma mesma cultivar.

A largura e a forma da base da folha unifoliolada foram avaliadas por BRANDÃO (1961) em estudos com 25 cultivares de soja. Para largura da base da folha, o pesquisador obteve a razão da maior largura da folha pelo seu comprimento, constatando valores de 0,71 a 1,03. Esse pesquisador classificou como folha de base larga quando o valor resultante foi igual a 1,0 e como de base estreita quando a razão foi menor que 1,0. Em relação à forma da base da folha, o pesquisador realizou uma caracterização visual, constatando que a maioria das cultivares possuía a forma da base auriculada, observada em 19 cultivares, e que cinco cultivares apresentaram a forma da base troncada e uma cultivar apresentava a forma da base acunheada. O mesmo autor relata que a forma da base da folha unifoliolada é uma característica que apresenta variabilidade entre as cultivares, dentro da mesma cultivar e inclusive na mesma planta.

Para avaliar a importância de uma variável como descritora várias técnicas estatísticas podem ser utilizadas. A análise discriminante de ANDERSON (1958) tem sido empregada em algumas culturas com objetivo de gerar funções discriminantes para classificar genótipos de feijão-vagem (Phaseolus vulgaris L.) (ABREU, 2001), discriminar espécies de Brachiaria spp. (ASSIS et al., 2003), diferenciar acessos do gênero Capscium spp. (SUDRÉ et al., 2006) e distinguir cultivares dos gêneros Cynodon e Digitaria (MOURA ZANINE et al., 2007). Entretanto, com soja ainda é incipiente o seu emprego, tendo sido relatado seu uso para avaliar a divergência genética entre linhagens de diferentes populações (BACKES, 2003).

$\mathrm{O}$ presente trabalho teve como objetivos identificar e avaliar novas características para fins de diferenciação de cultivares de soja.

\section{MATERIAL E MÉTODOS}

O trabalho foi realizado em casa de vegetação do Departamento de Fitotecnia (DFT), da Universidade Federal de Viçosa (UFV). Foram realizados quatro 
experimentos em quatro épocas diferentes, sendo dois no verão e dois no inverno. Os tratamentos foram constituídos de 11 cultivares de soja: "Viçoja", "UFV1", "UFV-16" (Capinópolis), "UFV-18" (Patos de Minas), "Conquista" (MG/BR-46), "Ocepar-3" (Primavera), "FT-Abyara", "FT-Estrela", "Emgopa-316", "DM-339", "M-SOY 9001", dispostos no delineamento inteiramente aleatorizado, com cinco repetições, sendo que cada unidade experimental foi constituída por um vaso com duas plantas. Para cada cultivar, foi utilizada uma amostra aleatória de sementes constituída de diferentes tamanhos.

Foram avaliadas sete características: a) Comprimento do hipocótilo $(\mathrm{CH})$ - medido em $\mathrm{cm}$ da superfície do solo até o nó cotiledonar no estádio vegetativo $\mathrm{V}_{2}$, b) Comprimento do epicótilo (CE) medido em $\mathrm{cm}$ a partir do nó cotiledonar até os nós das folhas unifolioladas no estádio vegetativo $\mathrm{V}_{3}$, c) Comprimento do pecíolo da folha unifoliolada (CPFU) - medido em cm a partir da inserção do pecíolo na haste principal até a inserção da folha unifoliolada no estádio vegetativo $V_{2}$, d) Forma da folha unifoliolada realizada em análise métrica $(\mathrm{cm})$ no estádio vegetativo $\mathrm{V}_{2}$. Para encontrar os valores, mediram-se o comprimento da inserção do folíolo até o ápice, a maior largura, a maior distância lateral direita a partir do ápice (DLD) e maior distância lateral esquerda a partir do ápice (DLE) da folha unifoliolada. Com base nesses dados, foram calculados os coeficientes da largura da base (CLB) e o coeficiente da forma da base

$(\mathrm{CFB}): \quad \mathrm{CLB}=\frac{\text { Largura }}{\text { Comprimento }} \quad$ e $\mathrm{CFB}=\frac{\frac{\mathrm{DLD}+\mathrm{DLE}}{2}}{\text { Comprimento }}$.

O primeiro requisito necessário para uma característica ser útil na diferenciação de cultivares é a existência de variabilidade genética. Com esse intuito, realizou-se a análise de variância. Posteriormente, procedeu-se a análise multivariada a fim de avaliar o potencial das características na discriminação genotípica quando consideradas em conjunto. Ambos os procedimentos foram realizados em cada época de semeadura. Para a análise de variância, seguiu-se o modelo estatístico $Y_{\mathrm{ij}}=\mu+\mathrm{G}_{\mathrm{j}}+\varepsilon_{\mathrm{ij}}$ em que: $\mu$ - média geral, $\mathrm{G}_{\mathrm{i}}$ - efeito da i-ésima cultivar, $\varepsilon_{\mathrm{ij}}$ - erro aleatório. Foi estimado o coeficiente de determinação genotípica dada por: $\mathrm{H}^{2}=\frac{\hat{\varphi}_{\mathrm{g}}}{\mathrm{QMT} / \mathrm{r}} \quad, \hat{\varphi}_{\mathrm{g}}=\frac{\mathrm{QMT}-\mathrm{QMR}}{\mathrm{r}} \mathrm{em}$ que: $\hat{\varphi}_{\mathrm{g}}$ - componente quadrático genético; QMTquadrado médio do tratamento (cultivar); QMRquadrado médio do resíduo; e $\mathrm{r}$ - número de repetições. Adotou-se o nível de significância $1 \%$ para testar a hipótese da igualdade das médias dos genótipos. Para o estudo da capacidade discriminatória das características, utilizou-se a metodologia de ANDERSON (1958), a qual foi realizada a partir de informações de indivíduos (repetição) sabidamente pertencentes a diferentes populações (cultivares). Com base nessas informações, foram geradas funções, que são combinações lineares das características avaliadas e que tiveram por finalidade promover a melhor discriminação entre os indivíduos. Para estabelecer a função discriminante de ANDERSON (1958), foram consideradas as populações $\Pi_{1}, \ldots, \Pi_{n}$, sendo $n \geq 2$, em que está associada a cada população $\Pi_{\text {uma }}$ distribuição multivariada. Considerando a igualdade das matrizes de covariâncias, as funções discriminantes foram obtidas de acordo com a expressão:

$$
\mathrm{D}_{\mathrm{i}}(\widetilde{\mathrm{x}})=\operatorname{In}\left(\mathrm{p}_{\mathrm{i}}\right)+\left(\widetilde{\mathrm{x}}-\frac{1}{2} \mu_{\mathrm{i}}\right) \cdot \sum^{-1} \mu_{\mathrm{i}}
$$

em que: $\mathrm{D}_{\mathrm{i}}(\widetilde{\mathrm{x}})$ - escore de classificação da i-ésima população, $\Sigma^{-1}$ - inversa da matriz de covariâncias, $\widetilde{x}$ vetor de variáveis representativas dos caracteres envolvidos na análise, $\mu_{i}$ - vetor de médias das variáveis avaliadas e $\mathrm{p}_{\mathrm{i}}$ - probabilidade a priori de um indivíduo pertencer a uma população i. O indivíduo foi classificado como pertencente a uma população (cultivar) para o qual ele tem maior escore de classificação, ou seja, o indivíduo de vetor de média $\widetilde{\mathrm{x}}$ será classificado no grupo $\Pi_{i} \operatorname{se}: \mathrm{D}_{\mathrm{i}}(\widetilde{\mathrm{x}})=\operatorname{máx}\left[\mathrm{D}_{1}(\widetilde{\mathrm{x}}), \mathrm{D}_{2}(\widetilde{\mathrm{x}}), \ldots, \mathrm{D}_{\mathrm{n}}(\widetilde{\mathrm{x}})\right]$. A eficiência das funções discriminantes em classificar as cultivares corretamente foi calculada pela taxa de erro aparente, conforme a expressão:

$$
\text { TEA }=\frac{1}{\mathrm{~N}} \sum_{\mathrm{i}=1}^{\mathrm{n}} \mathrm{m}_{\mathrm{i}},
$$

em que: $\mathrm{m}_{\mathrm{i}}=$ número de observações erradas em $\Pi_{i}$ e $\mathrm{N}$ = número total de classificações. As análises estatísticas foram realizadas utilizando o aplicativo computacional em Genética e Estatística, denominado Programa Genes (CRUZ, 2006).

\section{RESULTADOS E DISCUSSÃO}

A condição necessária para que uma característica possa ser útil na diferenciação de cultivares é a existência de variabilidade genética. Para todas as variáveis estudadas (comprimento do hipocótilo, comprimento do epicótilo, comprimento do pecíolo da $1^{\mathrm{a}}$ folha trifoliolada, comprimento da raque do folíolo terminal da $1^{\text {a }}$ folha trifoliolada e para as características da folha unifoliolada), verificaram-se diferenças significativas pelo teste F (Tabela 1). Observou-se também a consistência da variabilidade dessas características, tendo em vista os efeitos significativos para as quatro épocas de semeadura.

Os coeficientes de variação de todas as variáveis apresentaram valores de baixa até alta 
magnitude, variando de $1,62 \%$ para a característica CFB na época 3 (maio) a 41,32\% para CRFT na época 2 (fevereiro) (Tabela 1). Os altos valores de CV podem estar associados à não-homogeneização das características ao longo do processo de desenvolvimento das cultivares.

Na tabela 1 são apresentados também os coeficientes de determinação genotípica $\left(\mathrm{H}^{2}\right)$ para as características avaliadas nas quatro épocas de semeadura. Pode-se verificar grande influência genética para a maioria das características nas diferentes épocas, com valores oscilando entre 71,09 e 98,19\%, evidenciando pouco efeito ambiental sobre as características em questão.

De acordo com as funções discriminantes $\mathrm{D}_{\mathrm{i}}(\widetilde{\mathrm{x}})$, os indivíduos (informação da repetição) foram reclassificados em uma das 11 cultivares. Esse procedimento foi adotado partindo do princípio de que se desconhecia a qual cultivar pertenciam os indivíduos. $\mathrm{O}$ indivíduo em análise foi classificado como pertencente a uma determinada cultivar para a qual ele teve maior escore de classificação. Desse modo, para os indivíduos classificados como pertencentes a uma cultivar a que realmente pertencem, a classificação foi considerada correta e, quando os indivíduos foram alocados nas cultivares às quais não pertenciam, a classificação foi considerada incorreta. Quando os indivíduos de uma cultivar são classificados incorretamente em uma segunda cultivar, significa que ambas as cultivares são semelhantes para as características utilizadas na análise.

Os resultados para capacidade discriminatória das características consideradas em conjunto são apresentados nas tabelas 2 e 3 , nas quais são apresentadas as classificações corretas e incorretas dos indivíduos das cultivares para as quatro épocas de semeadura, considerando as sete características avaliadas (comprimento do hipocótilo, comprimento do epicótilo, comprimento do pecíolo da $1^{\text {a }}$ folha trifoliolada, comprimento da raque do folíolo terminal da $1^{\mathrm{a}}$ folha trifoliolada e o coeficiente da largura e da forma da base da folha unifoliolada). Na diagonal

Tabela 1 - Quadrados médios (QM), coeficientes de variação (CV) e coeficientes de determinação genotípica $\left(\mathrm{H}^{2}\right)$ das características comprimento do hipocótilo $(\mathrm{CH})$, comprimento do epicótilo (CE), comprimento do pecíolo da folha unifoliolada (CPFU), comprimento da raque do folíolo terminal da $1^{a}$ folha trifoliolada (CRFT), comprimento do pecíolo da $1^{\text {a }}$ folha trifoliolada (CPFT), coeficiente da largura da folha unifoliolada (CLB) e coeficiente da forma da base da folha unifoliolada (CFB) em cultivares de soja.

\begin{tabular}{|c|c|c|c|c|c|c|c|c|}
\hline \multirow{2}{*}{ Semeadura } & \multirow{2}{*}{ Estimativas } & \multicolumn{7}{|c|}{ 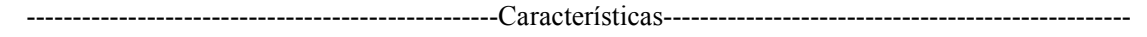 } \\
\hline & & $\mathrm{CH}$ & $\mathrm{CE}$ & $\mathrm{CPFU}$ & CRFT & CPFT & CLB & CFB \\
\hline \multirow{3}{*}{ dezembro } & QM & $3,78 * *$ & $6,37 * *$ & $0,49 * *$ & $0,30 * *$ & $1,96 * *$ & $0,03 * *$ & $0,01 * *$ \\
\hline & $\mathrm{CV}(\%)$ & 15,76 & 10,66 & 11,13 & 25,95 & 10,08 & 6,96 & 2,56 \\
\hline & $\mathrm{H}^{2}(\%)$ & 91,15 & 87,59 & 95,29 & 88,30 & 72,78 & 89,23 & 84,10 \\
\hline \multirow{3}{*}{ fevereiro } & QM & $1,00 * *$ & $8,38 * *$ & $0,55 * *$ & $0,36 * *$ & $6,81 * *$ & $0,01 * *$ & $0,04 * *$ \\
\hline & $\mathrm{CV}(\%)$ & 16,54 & 7,74 & 6,78 & 41,32 & 10,25 & 6,49 & 2,26 \\
\hline & $\mathrm{H}^{2}(\%)$ & 82,39 & 96,90 & 98,19 & 88,62 & 92,34 & 71,09 & 85,28 \\
\hline \multirow{3}{*}{ maio } & QM & $2,77 * *$ & $4,60 * *$ & $0,64 * *$ & $0,16 * *$ & $2,27 * *$ & $0,03 * *$ & $0,06 * *$ \\
\hline & $\mathrm{CV}(\%)$ & 10,52 & 5,52 & 9,10 & 21,02 & 8,43 & 3,63 & 1,62 \\
\hline & $\mathrm{H}^{2}(\%)$ & 95,58 & 95,04 & 96,85 & 93,26 & 90,44 & 97,06 & 94,75 \\
\hline \multirow{3}{*}{ Junho } & QM & $1,42 * *$ & $9,29 * *$ & $0,76 * *$ & $0,22 * *$ & $2,33 * *$ & $0,03 * *$ & $0,01 * *$ \\
\hline & $\mathrm{CV}(\%)$ & 9,96 & 12,72 & 11,60 & 24,68 & 10,58 & 4,54 & 2,35 \\
\hline & $\mathrm{H}^{2}(\%)$ & 90,10 & 89,27 & 95,29 & 89,74 & 75,49 & 94,60 & 87,41 \\
\hline
\end{tabular}

** Significativo a $1 \%$ de probabilidade de erro pelo teste $\mathrm{F}$. 
principal das tabelas, encontram-se as classificações corretas, sendo que para as demais células as classificações são incorretas. A identificação da classificação incorreta é verificada na linha das tabelas.

Em cada época de semeadura, foi realizado o total de 55 classificações. Observou-se que para semeadura de verão (dezembro) ocorreram sete classificações incorretas, sendo semelhantes as cultivares "Conquista", "Viçoja", "FT-Abyara", "Primavera" e "EMGOPA-316" (Tabela 2). Na semeadura de verão (fevereiro), cinco classificações foram incorretas, em que não foi possível distinguir as cultivares "UFV-18", "Conquista", "Viçoja" e "Primavera" (Tabela 2).

$\mathrm{Na}$ semeadura de inverno (maio), somente uma foi incorreta, não sendo possível diferenciar a cultivar Primavera (Tabela 3). Para a semeadura de inverno (junho), oito classificações foram incorretas, não sendo discriminadas as cultivares "UFV-18", "DM 339", "Viçoja", "UFV-1", "FT - Estrela" e "Emgopa-316" (Tabela 3)
A eficácia das funções discriminantes está associada principalmente à quantidade e à qualidade das variáveis consideradas na discriminação (CRUZ et al., 2004). Uma das maneiras de avaliar as funções discriminantes é por meio da taxa de erro aparente, as quais foram de $(12,73 \%$ e $9,09 \%)$ e $(1,82 \%$ e 16,36\%), respectivamente, para épocas de semeadura de verão (dezembro e fevereiro) e de inverno (maio e junho). ASSIS (2003), ao empregar a análise discriminante para distinguir acessos de Brachiaria spp., obteve a taxa de erro aparente de $12,29 \%$, concluindo que as funções discriminantes foram eficientes na discrimação das espécies.

No que diz respeito à falta de congruência na classificação das cultivares entre as diferentes épocas de semeaduras, uma provável explicação é a falta de homogeneidade das cultivares para as características avaliadas, que ainda não teriam sido consideradas durante o processo de seleção e melhoramento de cultivares. Considerando como exemplo a largura e a forma da base da folha unifoliolada,

Tabela 2 - Classificação correta e incorreta das 11 cultivares de soja conforme a análise discriminante de Anderson (em \%), considerando sete características no estádio vegetativo da semeadura de verão (dezembro e fevereiro).

\begin{tabular}{|c|c|c|c|c|c|c|c|c|c|c|c|}
\hline Cultivares & "UFV-16" & $\begin{array}{l}\text { "M-SOY } \\
9001 "\end{array}$ & “UFV-18' & , "Conquista" & $\begin{array}{l}\text { "DM- } \\
339 "\end{array}$ & "Viçoja " & "UFV-1" & $\begin{array}{c}\text { "FT- } \\
\text { Estrela" }\end{array}$ & $\begin{array}{c}\text { "FT- } \\
\text { Abyara" }\end{array}$ & "Primavera" & $\begin{array}{c}\text { "Emgopa- } \\
316 "\end{array}$ \\
\hline “UFV-16” & 100 & 0 & 0 & 0 & 0 & 0 & 0 & 0 & 0 & 0 & 0 \\
\hline "M-SOY 9001" & 0 & 100 & 0 & 0 & 0 & 0 & 0 & 0 & 0 & 0 & 0 \\
\hline “UFV-18” & 0 & 0 & 100 & 0 & 0 & 0 & 0 & 0 & 0 & 0 & 0 \\
\hline "Conquista" & 0 & 0 & 0 & 80 & 0 & 0 & 0 & 20 & 0 & 0 & 0 \\
\hline "DM-339” & 0 & 0 & 0 & 0 & 100 & 0 & 0 & 0 & 0 & 0 & 0 \\
\hline "Viçoja" & 0 & 0 & 0 & 0 & 0 & 80 & 0 & 0 & 20 & 0 & 0 \\
\hline "UFV-1" & 0 & 0 & 0 & 0 & 0 & 0 & 100 & 0 & 0 & 0 & 0 \\
\hline "FT-Estrela" & 0 & 0 & 0 & 0 & 0 & 0 & 0 & 100 & 0 & 0 & 0 \\
\hline "FT-Abyara" & 0 & 20 & 20 & 0 & 0 & 0 & 0 & 20 & 40 & 0 & 0 \\
\hline "Primavera" & 0 & 0 & 20 & 0 & 0 & 0 & 0 & 0 & 0 & 80 & 0 \\
\hline "Emgopa-316" & 0 & 0 & 0 & 0 & 0 & 0 & 0 & 0 & 0 & 20 & 80 \\
\hline Cultivares & "UFV-16" & $\begin{array}{l}\text { "M-SOY } \\
9001 "\end{array}$ & 'UFV-18' & " "Conquista" & $\begin{array}{l}\text { "DM- } \\
339 "\end{array}$ & "Viçoja" & "UFV-1" & $\begin{array}{c}\text { "FT- } \\
\text { Estrela" }\end{array}$ & $\begin{array}{c}\text { "FT- } \\
\text { Abyara" }\end{array}$ & "Primavera" & $\begin{array}{c}\text { "Emgopa- } \\
316 "\end{array}$ \\
\hline "UFV-16" & 100 & 0 & 0 & 0 & 0 & 0 & 0 & 0 & 0 & 0 & 0 \\
\hline "M-SOY 9001" & 0 & 100 & 0 & 0 & 0 & 0 & 0 & 0 & 0 & 0 & 0 \\
\hline "UFV-18” & 0 & 0 & 60 & 0 & 0 & 0 & 0 & 0 & 20 & 0 & 20 \\
\hline "Conquista" & 0 & 0 & 20 & 80 & 0 & 0 & 0 & 0 & 0 & 0 & 0 \\
\hline “DM-339” & 0 & 0 & 0 & 0 & 100 & 0 & 0 & 0 & 0 & 0 & 0 \\
\hline "Viçoja" & 0 & 0 & 0 & 0 & 0 & 80 & 0 & 0 & 20 & 0 & 0 \\
\hline "UFV-1" & 0 & 0 & 0 & 0 & 0 & 0 & 100 & 0 & 0 & 0 & 0 \\
\hline "FT-Estrela" & 0 & 0 & 0 & 0 & 0 & 0 & 0 & 100 & 0 & 0 & 0 \\
\hline "FT-Abyara" & 0 & 0 & 0 & 0 & 0 & 0 & 0 & 0 & 100 & 0 & 0 \\
\hline "Primavera" & 20 & 0 & 0 & 0 & 0 & 0 & 0 & 0 & 0 & 80 & 0 \\
\hline "Emgopa-316" & 0 & 0 & 0 & 0 & 0 & 0 & 0 & 0 & 0 & 0 & 100 \\
\hline
\end{tabular}


Tabela 3 - Classificação correta e incorreta das cultivares de soja conforme a análise discriminante de Anderson (em \%), considerando sete características no estádio vegetativo da semeadura de inverno (maio e junho).

\begin{tabular}{|c|c|c|c|c|c|c|c|c|c|c|c|}
\hline Cultivares & "UFV-16" & $\begin{array}{l}\text { "M-SOY } \\
9001 "\end{array}$ & "UFV-18” “" & "Conquista" & $\begin{array}{l}\text { "DM- } \\
339 "\end{array}$ & "Viçoja" & "UFV-1" & $\begin{array}{c}\text { "FT- } \\
\text { Estrela" }\end{array}$ & $\begin{array}{c}\text { "FT- } \\
\text { Abyara" }\end{array}$ & "Primavera" & $\begin{array}{l}\text { "Emgopa- } \\
316 "\end{array}$ \\
\hline "UFV-16" & 100 & 0 & 0 & 0 & 0 & 0 & 0 & 0 & 0 & 0 & 0 \\
\hline "M-SOY 9001" & 0 & 100 & 0 & 0 & 0 & 0 & 0 & 0 & 0 & 0 & 0 \\
\hline "UFV-18" & 0 & 0 & 100 & 0 & 0 & 0 & 0 & 0 & 0 & 0 & 0 \\
\hline "Conquista" & 0 & 0 & 0 & 100 & 0 & 0 & 0 & 0 & 0 & 0 & 0 \\
\hline “DM-339” & 0 & 0 & 0 & 0 & 100 & 0 & 0 & 0 & 0 & 0 & 0 \\
\hline "Viçoja" & 0 & 0 & 0 & 0 & 0 & 100 & 0 & 0 & 0 & 0 & 0 \\
\hline "UFV-1" & 0 & 0 & 0 & 0 & 0 & 0 & 100 & 0 & 0 & 0 & 0 \\
\hline "FT-Estrela" & 0 & 0 & 0 & 0 & 0 & 0 & 0 & 100 & 0 & 0 & 0 \\
\hline "FT-Abyara" & 0 & 0 & 0 & 0 & 0 & 0 & 0 & 0 & 100 & 0 & 0 \\
\hline "Primavera" & 0 & 0 & 0 & 0 & 0 & 0 & 0 & 0 & 20 & 80 & 0 \\
\hline "Emgopa-316" & 0 & 0 & 0 & 0 & 0 & 0 & 0 & 0 & 0 & 0 & 100 \\
\hline Cultivares & "UFV-16" & $\begin{array}{l}\text { "M-SOY } \\
9001 "\end{array}$ & “UFV-18” “" & "Conquista" & $\begin{array}{l}\text { "DM- } \\
339 "\end{array}$ & "Viçoja" & "UFV-1" & $\begin{array}{c}\text { "FT- } \\
\text { Estrela" }\end{array}$ & $\begin{array}{c}\text { "FT- } \\
\text { Abyara" }\end{array}$ & "Primavera" & $\begin{array}{c}\text { "Emgopa- } \\
316 "\end{array}$ \\
\hline "UFV-16" & 100 & 0 & 0 & 0 & 0 & 0 & 0 & 0 & 0 & 0 & 0 \\
\hline "M-SOY 9001" & 0 & 100 & 0 & 0 & 0 & 0 & 0 & 0 & 0 & 0 & 0 \\
\hline “UFV-18" & 0 & 0 & 80 & 0 & 0 & 20 & 0 & 0 & 0 & 0 & 0 \\
\hline "Conquista" & 0 & 0 & 0 & 100 & 0 & 0 & 0 & 0 & 0 & 0 & 0 \\
\hline “DM-339” & 0 & 0 & 0 & 0 & 80 & 20 & 0 & 0 & 0 & 0 & 0 \\
\hline "Viçoja" & 0 & 0 & 0 & 0 & 0 & 80 & 0 & 0 & 20 & 0 & 0 \\
\hline "UFV-1" & 20 & 0 & 0 & 0 & 40 & 0 & 40 & 0 & 0 & 0 & 0 \\
\hline "FT-Estrela" & 0 & 0 & 0 & 20 & 0 & 0 & 0 & 80 & 0 & 0 & 0 \\
\hline "FT-Abyara" & 0 & 0 & 0 & 0 & 0 & 0 & 0 & 0 & 100 & 0 & 0 \\
\hline "Primavera" & 0 & 0 & 0 & 0 & 0 & 0 & 0 & 0 & 0 & 100 & 0 \\
\hline "Emgopa-316" & 0 & 0 & 0 & 20 & 0 & 0 & 20 & 0 & 0 & 0 & 60 \\
\hline
\end{tabular}

DORCHESTER (1945) e BRANDÃO (1961) obtiveram resultados semelhantes ao observar variabilidade para essas características entre cultivares, bem como dentro de uma mesma cultivar. Outra possível causa que pode ter contribuído para as diferenças das classificações das cultivares é o fato de ter sido utilizada, na instalação dos experimentos, amostra não-padronizada de sementes, embora exista controvérsia entre resultados obtidos em relação à interferência do tamanho de sementes no comprimento do hipocótilo (KNITTLE \& BURRIS, 1979; COSTA et al., 1999).

Deve-se ressaltar que as cultivares que não foram distinguidas nas diferentes épocas de semeadura não implica a inutilidade das características para diferenciar cultivares, pois o número de características adotadas para estabelecerem as funções discriminantes foi limitado. Desse modo, ao se incluir características já utilizadas como descritoras com as novas identificadas, pode-se melhorar a eficiência da capacidade discriminatória das funções discriminantes.

\section{CONCLUSÕES}

As cultivares de soja avaliadas apresentaram variabilidade genética para as características comprimento do hipocótilo, comprimento do epicótilo, comprimento do pecíolo da folha unifoliolada, comprimento do pecíolo da primeira folha trifoliolada, comprimento da raque do folíolo terminal da primeira folha trifoliolada e forma da folha unifoliolada, podendo ser úteis como descritoras adicionais de soja.

A eficiência das funções discriminantes com base nas novas características entre épocas de semeadura foi de $(12,73 \%$ e $9,09 \%)$ e $(1,82 \%$ e $16,36 \%)$, respectivamente, para épocas de semeadura de verão (dezembro e fevereiro) e de inverno (maio e junho).

\section{AGRADECIMENTOS}

Os autores agradecem à Coordenação de Aperfeiçoamento de Pessoal de Nível de Superior (CAPES), pelo apoio financeiro. 


\section{REFERÊNCIAS}

ABREU, F.B. Análise multivariada na determinação da divergência genética em feijão-vagem (Phaseolus vulgaris L.) de crescimento indeterminado. 2001. 73f. Dissertação (Mestrado em Produção Vegetal) - Curso de Pós-graduação em Produção Vegetal, Universidade Estadual do Norte Fluminense Darcy Ribeiro.

ANDERSON, T.W. An introduction to multivariate statistical analysis. New York: John Wiley \& Sons, 1958. 242p.

ASSIS, G.M.L. et al. Discriminação de espécies de Brachiaria baseada em diferentes grupos de caracteres morfológicos. Revista Brasileira de Zootecnia, Viçosa, v.32, n.3, p.576$584,2003$.

BACKES, R.L. Desempenho agronômico, resistência ao cancro-da-haste e análise discriminante em soja (Glycine $\max ($ L.) Merrill). 2003. 141f. Tese (Doutorado em Genética e Melhoramento) Curso de Pós-graduação em Genética e Melhoramento, Universidade Federal de Viçosa.

BRANDÃO, S.S. Contribuição ao estudo de variedades de soja. Experientia, Viçosa, v.1, n.4, p.119-199, 1961.

COSTA, J.A. et al. Comprimento e índice de expansão radial do hipocótilo de cultivares de soja. Ciência Rural, Santa Maria, v.29, n.4, p.609-612, 1999.

CRUZ, C.D. Programa GENES: versão Windows, aplicativo computacional em genética e estatística. Análise multivariada e simulação. Viçosa: UFV, 2006. 175p.

CRUZ, C.D. et al. Modelos biométricos aplicados ao melhoramento genético II. Viçosa: UFV, 2004. 480p.

DORCHESTER, C.S. Seed and seedling characters in certain varieties of soybeans. Journal American Society Agronomy, Madison, v.37, n.1, p.223-232, 1945.
EMBRAPA, 2006. Sistema de produção 11: tecnologias de produção de soja - região central do Brasil 2007. Londrina: EMBRAPA SOJA, 2006, 225p.

FEHR, W.R.; CAVINESS, C.E. Stage of soybean development. Ames: Iowa State University of Science and Technology, 1977. 11p. (Special report 80).

GRILLI, G.V. Legislação brasileira sobre proteção de cultivares. Palestras. In: ENCONTRO DA SOCIEDADE BRASILEIRA DE MELHORAMENTO DE PLANTAS REGIONAL DF, 2005, Brasília. Documentos... Brasília: EMBRAPA Recursos Genéticos e Biotecnologia, 2005 14p

KNITTLE, K.H.; BURRIS, J.S. Soybean hypocotyl growth under field conditions. Crop Science, Madison, v.19, n.1, p.37-41, 1979.

MÜLLER, L. Taxionomia e morfologia. In: MIYASAKA, S. MEDINA, J.C. (Eds). A soja no Brasil. Campinas: Instituto de Tecnologia de Alimentos, 1981. p.65-104.

NETO, M.O. de V. et al. Lei de proteção de cultivares. In: BORÉM, A. (Ed.). Melhoramento de espécies cultivadas. Viçosa: UFV, 2005. p.931-960.

ROSSINI, M.C. et al. Caracterização de 26 cultivares de soja [Glycine max (L.) Merrill] recomendadas para a região Sul Brasil. Revista Brasileira de Sementes, Brasília, v.17, n.2, p. $227-235,1995$

SUDRÉ, C.P. et al. Variáveis multicategóricas na determinação da divergência genética entre acessos de pimenta e pimentão Horticultura Brasileira, Campinas, v.24, n.1, p.88-93, 2006.

MOURA ZANINE, A. de et al. Uso de funções discriminantes para comparação de cultivares dos gêneros Cynodon e Digitaria quanto à produção de matéria seca e teores de macronutrientes. Asociación Latinoamericana de Producción Animal, v.15, n.4, p.152-156, 2007.

NÓBREGA, L.H.P.; VIEIRA, R.D. Avaliação e classificação de cultivares de soja quanto ao comprimento do hipocótilo, sob condições de laboratório e de casa de vegetação. Revista Brasileira de Sementes, Brasília, v.17, p.160-164, 1995. 